\title{
Expressive Maps
}

Santiago V. Lombeyda

California Institute of Technology

slombey@caltech.edu

Data courtesy of:

Barbara Wold Lab

California Institute of Technology

Original tools developed in collaboration with: Katherine Fisher-Aylor

Wold Lab

California Institute of Technology

Set of three gene expression maps, wallmounted, (c) 2013 Santiago Lombeyda.

\section{Santiago V. Lombeyda}

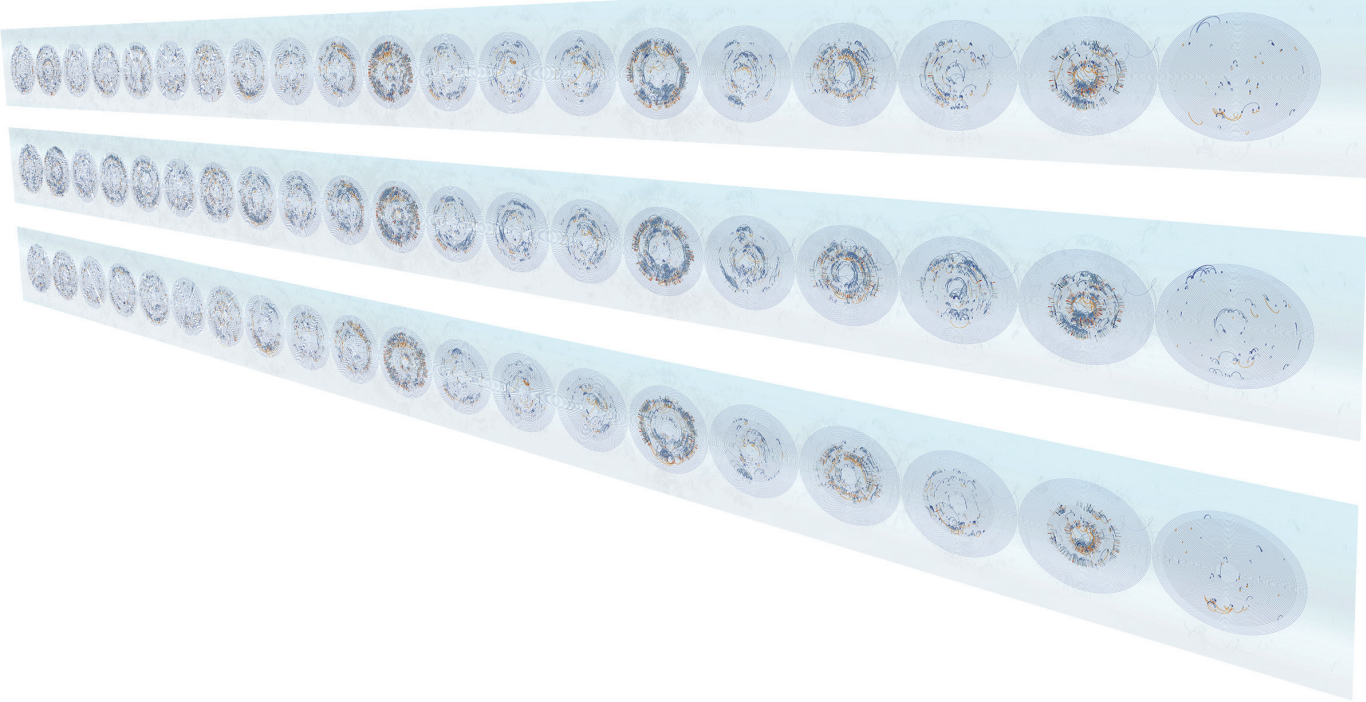

Expressive Maps is an artistic visualization of a complete mouse DNA sequence, taken from embryonic mouse muscle tissue, stretched out in a line. Each individual spiral represents a single chromosome (mice have 20 , versus 23 in humans), and active sections perform calls across the corresponding chromosome addresses. It displays three stages of development: before specialization, 60 hours after specialization, and 60 hours post-specialization with an inhibitor present. Each stage has been printed on vellum, so one "map" can be placed on top of another to reveal differences.

The pioneering science of genetics and molecular biology works on trying to understand amazingly complex systems that regulate life-systems encapsulated at a microscopic scale. Despite their size, these systems carry all the information necessary to describe, architect, regulate, and enable our existence. 


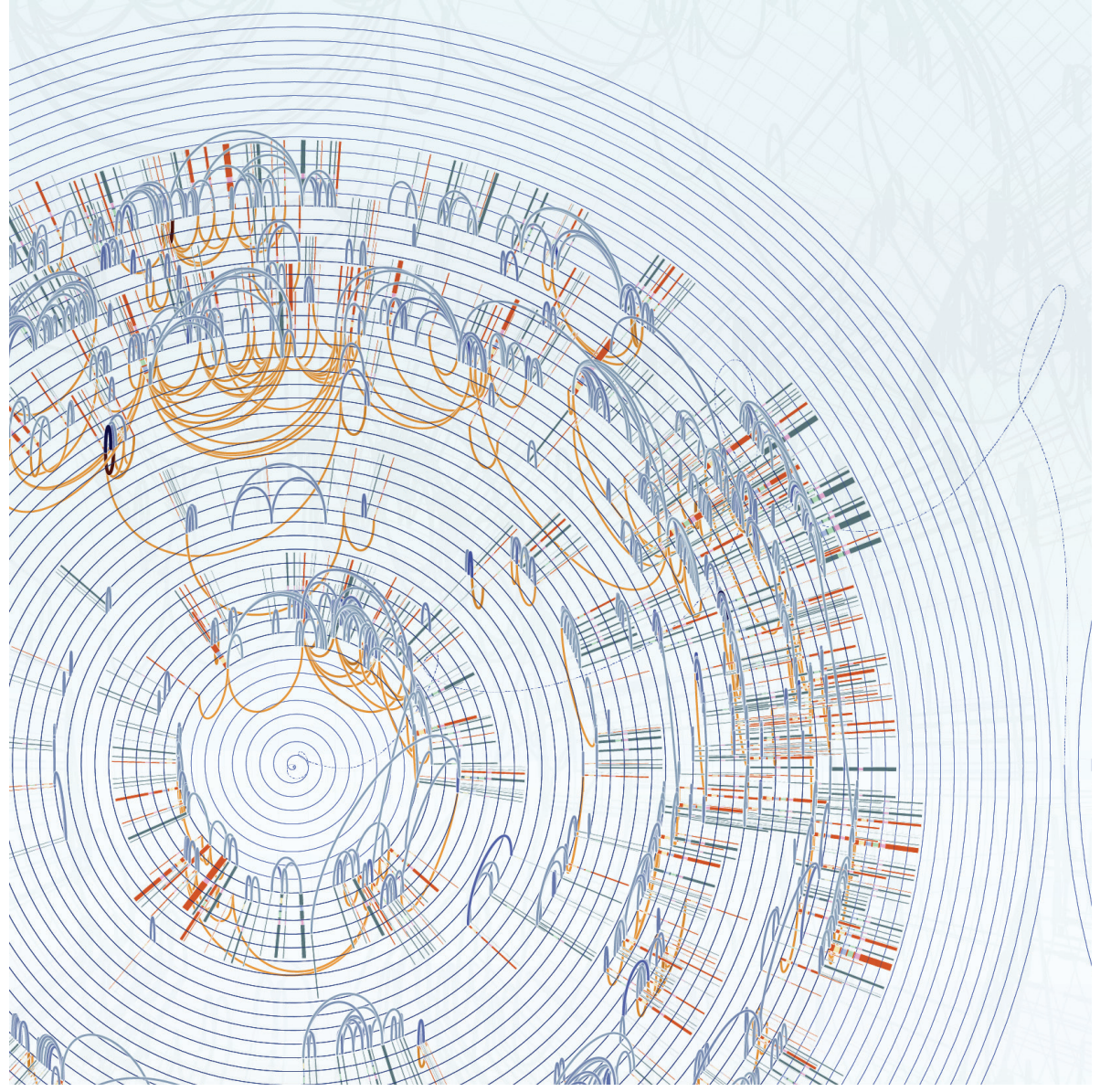

At the core are macromolecules (DNA) too small to observe "in action." And yet if we were to stretch it out, one single DNA chain would measure between three and nine feet in length. Using experiments, we can measure the rate of "calls" across the DNA, triggering or inhibiting specific segments or genes. Studying these interactions before and after specialization (the process of self-determining the type of specific muscle cell it will become) provides a key to understanding cell dynamics. Graphics visualization tools are valuable tools in this challenging area of active research.

These expressive maps are not only scientifically accurate and meaningful, but they are snapshots of a dynamic system, minute and yet quite "grandiose," and ultimately awe-inspiring. 5in $x$ 5in Zoomed-in detail of one chromosome, (0) 2013 Santiago Lombeyda. 